\title{
Basic terminology of eye-tracking research
}

\author{
Agnieszka ANDRYCHOWICZ-TROJANOWSKA \\ Uniwersytet Warszawski/ University of Warsaw \\ E-mail: a.andrychowicz@uw.edu.pl
}

\begin{abstract}
:
The article is aimed at making the reader familiar with the basics of eye tracking as well as its terminology and at making them aware of the fact that eye-tracking supported linguistic and glottodidactic research, being conducted in Poland, is getting more and more popular. The article gives basic information about eye tracking and two most crucial eye movements, i.e. fixations and saccades. It also lists the most important academic research centers in Poland that conduct linguistic research with the help of eye tracking. The next, and the most important, part of the article is a short characteristics of the chosen eyetracking parameters that are commonly used in different types of eye-tracking data analysis. They were chosen on the basis of the author's own research experience in the field of experimental eye-tracking glottodidactics.
\end{abstract}

Keywords:

eye tracking, fixation, saccade, AOI, glottodidactics, terminology

\section{Introduction}

Technological development and its achievements that have been observed for a few decades is now present not only in such branches of science as medicine, physics, chemistry etc. Finally, also linguists can use the most advanced devices enriching their research with the newest applications. The example of a technologically advanced device that is more and more often present in the linguistic studies is an eye tracker that measures eye movements.

The use of eye tracking in glottodidactics was described in some of my previous papers (see for example A. Andrychowicz-Trojanowska 2016). The following article is a continuation of the theme, however, this time its goal is not to present the results of the research but to make the reader more familiar with eye tracking, eye-tracking terminology and eye-tracking parameters, especially those that are useful in linguistic and glottodidactic research. To do it, eye tracking itself will be briefly characterized, fixations and saccades (the most important eye movements) will be presented, basic linguistic academic research centers that use eye tracking will be listed, and, finally, the most important and useful eye-tracking parameters will be shortly characterized.

\section{Eye tracking in a nutshell}

The interest in human's eye and eye movements has a very long history but only since the mid-1970s it has become possible to really follow it and check it. The real 
breakthrough in that type of research was started by the development of eye-tracking methodology and eye-tracking tools which are now widely used in different branches of human activity. Eye trackers are present in such areas as neuroscience, psychology, psychiatry and psycholinguistics, usability, industrial engineering, human factors and ergonomics, marketing (market research), advertising, computer science, gaze based interaction etc. (A. Duchowski 2007) and they help to understand such activities as reading, scanning, visual stimuli processing (L. Lorigo et al. 2008), cognitive load etc.

Eye movements are the human behaviour that occurs on average three times per second, it is an indicator of the information which is being received at the particular moment by the subject (P. Soluch/ A. Tarnowski 2013). Eye tracking allows to observe and analyse the way the person looks at the object, so it may be possible to see in details what is at the central direction of gaze as well as to follow along the path of the visual attention of the observer (A. Duchowski 2007: 3). Eye tracking is based on an eye/mind hypothesis by M.A. Just and P.A. Carpenter (1976) saying that the area of interest is indicated by the location of a fixation (when looking at a visual display and completing a task) as well as on the assumption that the easiness or difficulty of the display to be processed influences the duration of fixations and the pattern of eye movements (J.A. Renshaw et al. 2004).

There are two basic eye movements, i.e. fixations and saccades. Fixations stabilize the retina over an object of interest which is stationary (A. Duchowski 2007: 46). They are the focuses of our eyes on a particular scene lasting for approximately 200-300 milliseconds. Saccades are rapid eye movements occurring between fixations and lasting, depending on a source, 40-50 milliseconds (L. Lorigo et al. 2008) or 30-80 ms (K. Holmqvist et al. 2011). They reposition the fovea to a new location (A. Duchowski 2007). During a saccade the eyes are moving very fast (the velocity can be even $500^{\circ}$ per second) and because of that no new information is obtained during a saccade (K. Rayner 1998). However, during the fixation the eye is not completely still - there are three types of micro-movements that it does when fixating: tremor (also called nystagmus; it is a small movement of c.a. $90 \mathrm{~Hz}$ frequency whose role is not clear), drifts (slow movements that take an eye away from the fixation center), microsaccades (they quickly bring the eye back to its original position) (K. Holmqvist et al. 2011: 22-23, see also S. Martinez-Conde et al. 2004, K. Rayner 1998). Saccades hardly ever take the shortest possible path between two fixations and that is why they can be of several shapes and curvatures (K. Holmqvist et al. 2011). More saccades are the indicator of more searching (J.H. Goldberg/ X. Kotval 1999). What is more, one should realize that there are some other eye movements that should be distinguished from saccades, i.e. pursuit, vergence and vestibular eye movements. When one's eyes follow a moving target, the pursuit eye movements occur; when one moves their eyes inward, toward each other to fixate on an object, vergence eye movements occur; when one rotates their eyes in order to compensate for body movements (including head movements) as to maintain the same direction of vision, vestibular eye movements occur (K. Rayner 1998: 373).

K. Rayner (1998: 372) distinguishes three eras of eye movement research. According to him the first era was begun by Louis E. Javal in 1879 by his observations 
about the role of eye movements in reading and lasted until about 1920. At that time the interest was put on such issues as saccadic suppression, saccade latency, the size of perceptual span. Then the second era came, coinciding with the behaviorist movement in experimental psychology. In this era the works of G.T. Buswell (in 1935) on scene perception and of M.A. Tinker (in 1946) on reading occurred. Unfortunately, between the late 1950s and the mid-1970s almost no research on eye movements was held. The mid-1970s is the beginning of the third and the most important era lasting till today. Since then the large improvements in the eye movement recording system have been made owing to which the measurements are more and more accurate and more easily obtained. It also became possible to interface eye-tracking systems with laboratory computers and, as a consequence, collect and analyze large amounts of data.

Eye trackers are advanced physiological systems of measurements (K. Holmqvist et al. 2011: 11), they track and record the position of where the eye is looking at and in what order. That allows to identify the areas which are brought to the participant's attention. The eye tracker sends the processed images to a computer with which it is integrated, and the software analyses the data to present the results in an effective way (http://www.neurodevice.pl/en/services/eye-tracking).

Nowadays eye trackers that are very often used are the video-based ones that have an infrared illumination and an eye video camera. Usually for head-mounted eye trackers there is also an additional scene camera (K. Holmqvist et al. 2011). Tracking is possible because reflections on the surface of participant's eyes are created by infrared light sources (it is called the corneal reflection) and the location of that reflection is then compared by the system to the location of their pupil (as the participant moves their eyes, the location of the corneal reflection relative to the pupil changes) (T. Tullis/ B. Albert 2013: 166).

Taking into consideration all the differences between the devices (for example the position of cameras, the position of illuminations, the type of produced data, the way the output can be analyzed) there can be distinguished three types of eye trackers: (1) the most popular static eye trackers that put the illumination and eye camera in front of the participant, on the table. Tower-mounted static eye trackers are in a close contact with the participant (they restrain head movements). Remote static eye trackers are not attached to the head (or there is very little attachment) - usually the stimuli are presented on the computer monitor; (2) head-mounted eye trackers that put illuminations and cameras on the participant's head (they are mounted on a helmet, cap or a pair of glasses). A scene camera records the stimulus, i.e. the scene of view; (3) head-mounted eye trackers equipped with a head-tracker that calculates the position of the head in space (K. Holmqvist et al. 2011: 51).

\section{Eye tracking in linguistic research}

Except for the areas of human activity listed above, eye tracking is more and more often used in linguistics (see S. Grucza 2011). In Poland there are a few academic centers that conduct the linguistic research with the help of eye-tracking methodology, for example Adam Mickiewicz University, Faculty of English (see for example 
A. Chmiel/ I. Mazur 2013 etc.) and Warsaw University. At the Faculty of Applied Linguistics of Warsaw University there are two centers worth mentioning: AVT Lab (see for example A. Szarkowska et al. 2013) and LELO (Laboratorium Eksperymentalnej Lingwistyki Okulograficznej - Eye-Tracking Experimental Linguistics Laboratory) (see for example S. Grucza/ M. Płużyczka/ J. Zając 2013, S. Grucza/ M. Płużyczka/ P. Soluch 2014, S. Grucza 2013, M. Płużyczka 2013, 2015, A. Kudłaj et al. 2014, A. Bonek 2016, A. Andrychowicz-Trojanowska 2015, 2016, see also lelo.uw.edu.pl). LELO is the first laboratory of that type in Poland. It is aimed at carrying out research in the field of linguistics but with the support of eye tracking. The goal is to verify and complement by eye-tracking methodology the previous findings of translation studies and glottodidactics (S. Grucza/ M. Płużyczka/ J. Zając 2013: 8).

Because of the fact that eye tracking is still not too popular in the field of foreign language teaching and learning (i.e. glottodidactics) in Poland I have been calling this new way of supporting that type of research as experimental eye-tracking glottodidactics (however, the first one to use the name eye-tracking glottodidactics (Polish glottodydaktyka okulograficzna) was S. Grucza - see, for example, S. Grucza 2016). It should be said that some of the projects are conducted by Eye-Tracking Laboratory at SWPS University of Social Sciences and Humanities, Faculty of Psychology at Warsaw University and Laboratory HD at Faculty of Social Sciences of the John Paul II Catholic University of Lublin.

In the analysis of the results recorded by the eye tracker a researcher can use some particular parameters out of a big variety of them. The eye-tracking parameters used are different depending on the character and the aim of the study. For example, M. Płużyczka (2015) in her eye-tracking sight translation research, based her analysis on the following parameters (their names are typical for SMI RED eye trackers and may vary from the names used by different producers in other eye trackers in the same context): total reading time, dwell time, fixation count, revisits, average fixation, pupil dilation. She also used graphic representations, i.e. heat maps and scan paths. On the other hand, I. Krejtz, A. Szarkowska, K. Krejtz (2013) in their eye-tracking audiovisual research chose the following: subject hit count, number of fixations, fixation time percent, first fixation duration, transition matrix. I, in my English textbook analysis, chose, among others, subject hit count, revisits average, fixation count average, fixation time average, fixation count total, fixation time total, dwell time, transition matrix, AOI sequence chart.

It is important to realise that different stimuli and different aim of research require different sets of parameters to be analysed. The software gives a lot of them so it is the researcher that should choose the most proper and the most effective ones. In case of my research it cannot be forgotten that the contemporary textbook of English that is used in the Polish secondary schools consists of the text part and graphic part. Both of them are strictly related - the graphic part includes, among others, illustrations that are a kind of stimulating material for students, very often related to the main text. As such they are integrated and should not be analysed separately. Because of that they differ from the stimuli of a sight translation research and also from the audiovisual 
stimuli. The last one is, on one hand, similar, because it also comprises of the text (in the form of subtitles) and the picture, but, on the other hand, they differ because of the motion of the picture and the sound which is an integral part of the film.

Still there is not so much research combining text and picture, although it is changing. A lot of interest has been put on either reading or looking at pictures (K. Rayner 1978, 1998), but not much on the situation when the text and pictures are integrated in the comprehension process (K. Rayner et al. 2001). It is surprising because people are still surrounded by that type of combined information (S.A. Duffy 1992). The greatest example of that, except for newspapers, subtitled movies etc., are textbooks, for example English ones used at Polish secondary schools.

\section{Common eye-tracking metrics in glottodidactic research}

On the basis of the experience out of my research and the analysis of the collected data, as well as the character of the stimuli, the set of useful eye-tracking parameters that seem to be of most research value in that type of (glottodidactic) research can be listed. The suggested set of the parameters is as follows (all of them will be further described in this chapter): subject hit count, revisits, fixation duration, fixation count, saccade count, dwell time, spatial density, transition matrix, blink rate and pupil size, scan paths, heat maps and AOI sequence charts (all these names are used in SMI RED eye-tracking systems and the parameters they name can be called in a different way in eye tracking software of other producers). It should also be said that such parameters as fixation duration, first fixation duration, dwell time, total dwell time are called position duration measures because they all are related to how long the gaze of a participant stays within a position (K. Holmqvist et al. 2011). It needs to be emphasized that all eye-tracking data is either for one participant or for more than one participant. It is the researcher who sets the number of participants the data is given for.

To describe the parameters further it is necessary to introduce an area of interest (AOI) as the majority of the parameters is given by the software for the particular areas of interest. AOIs are the regions in the stimulus that the researcher is especially interested in gathering data about (K. Holmqvist et al. 2011: 187); as such they are chosen by the researcher and can be changed and/or selected during the analysis of the data. They are also used to include or exclude some parts of the stimulus from the further analysis (for example, if a stimulus is a box of cornflakes, AOIs can be the producer's logo and date of expiry).

The parameter it is worth starting the analysis with is a subject hit count (also called hit ratio), i.e. the information (counts and/or percentage) how many participants out of the selected ones looked at least once at the particular area of interest. In other words, it is the number of participants that saw a particular AOI (T. Tullis/ B. Albert 2013). On the basis of subject hit count it can be noticed which AOIs were not looked at.

Revisits (also called returns) are defined as a transition to an AOI that has already been visited (K. Holmqvist et al. 2011), they are the second and more glance at the previously viewed object (AOIs). To be more specific, they are the sum of all participant's glances at the particular AOI minus 1 (i.e. minus the very first glance 
which is the first visit).

One of the most used eye-tracking measures is fixation duration (also called fixation time), i.e. duration of a particular fixation. It is believed that the longer fixation, the more time is spent on interpreting (J.H. Goldberg/ X. Kotval 1999) and that means the more complicated it (i.e. object) was for a reader (M. Płużyczka 2015). It is also said that the longer fixation duration, the most problematic perception of the fixated object (J.A. Renshaw et al. 2004, see also M. Płużyczka 2015) as the length of this parameter indicates difficulty or easiness of extracting information (M.A. Just/ P.A. Carpenter 1976). Fixation duration parameter may be further divided into fixation time average, first fixation duration, gaze duration (AOI fixations, sum of fixations). Fixation time average is a sum of fixation durations of all subjects divided by their number. First fixation duration in an AOI (also called FFD), though, reflects the time taken for recognition and idenitification on a part of the stimulus image, which are fast processes (K. Holmqvist et al. 2011).

Fixation count is a number of fixations in a trial and is correlated to total dwell time (K. Holmqvist et al. 2011). It is said to be the most often used parameter in eyetracking research (R.J.K. Jacob/ K.S. Karn 2003). The higher number of fixations (overall fixations), the poorer search capacity of a participant or the poorer structure of the stimuli. That means that if the informativeness of the stimuli is high (in other words, the structure of the stimuli helps the process of information search), the number of fixations decreases (J. Grobelny et al. 2006). On the other hand, more fixations on a particular AOI may indicate that the AOI is more important and/or more noticeable to the participant than the others (A. Poole et al. 2004). The parameter can be used as an indicator of semantic importance of a piece of stimulus (in scene perception search, for example, it was proved that on semantically informative areas there were significantly more fixations), search efficiency and difficulty (it is thought the parameter is negatively correlated with efficiency of search), experience (it is proved that in their area of experience experts have fewer fixations), memory build-up, properties of words in reading (long composite words or unfamiliar words have more fixations), dysfunctions (dyslexic readers in general make more fixations), age, sex etc. (K. Holmqvist et al. 2011).

Saccade count is defined as a number of saccades in a trial. The number of saccades is strictly related to the spatial organization of information in the stimuli, i.e. the poorer organization, the more saccades (J. Grobelny et al. 2006).

Dwell time (also called gaze duration) is understood as one visit (from entry to exit) in an AOI and is a sum of all fixations and saccades in a particular AOI (K. Holmqvist et al. 2011). In other words, it is the total amount of time spent looking within a particular AOI (T. Tullis/ B. Albert 2013). Dwells can be calculated only if the AOIs were set for the stimulus (that differs dwells from fixations which can be calculated even if there are no AOIs for the stimuli) (K. Holmqvist et al. 2011). Dwell time is used to check the participant's interest in an object or to check its level of informativeness. A higher dwell time may also be an indicator of uncertainty and poorer awareness of situation, of difficulty in extracting information from a display. In the eye-tracking research of reading processes longer dwell time is related to less 
frequent words. Dwell time is also a key-parameter in gaze-based interaction with computers as it is the most important criterion for activating the button function on the screen. The sum of all dwell times in the particular AOI over a trial is called total dwell time (K. Holmqvist et al. 2011).

Spatial density is a spatial distribution of gazepoint samples covering a stimulus. If spatial density is smaller, the search is more direct (J.H. Goldberg/ X. Kotval 1999). Fixation spatial density shows if the search was focused and efficient (evenly spread fixations indicate inefficient and widespread search) (L. Cowen et al. 2002). The given parameter is useful in case of the research aimed at analyzing spatial distribution of the stimuli etc.

The frequency of eye movement transitions between the AOIs can be shown in the form of transition matrix (it is a table showing the number of transitions to and from each AOI). Frequent transitions are an indicator of inefficient scanning accompanied by extensive search (J.H. Goldberg/ X. Kotval 1999).

There are also two parameters that are the indicators of cognitive load, i.e. blink rate and pupil size (also called pupil dilation, pupil diameter). It is assumed that a lower blink rate indicates a higher workload, whereas a higher blink rate may be related to fatigue (A. Poole/ L.J. Ball 2006). In case of pupil diameter, larger pupils may be an indicator of more cognitive effort, although both these parameters may be caused by some other factors (A. Poole/ L.J. Ball 2006). That is why they are not so often used in eye-tracking analysis.

All the above listed and described parameters are only a few out of many that are generated by the software. However, all of them are related to fixations and saccades, i.e. the most basic eye movements. Except for the numerical data the examples of which were shown, the software gives some representations in a graphic form. i.e. scan paths, heat maps, AOI sequence charts and different graphs. Scan paths (also scan paths, scan patterns, search patterns, scan sequences, gaze sequences, fixation tracks, eye-movement patterns) are visualizations of "routes of oculomotor events through space within a certain timespan" (K. Holmqvist et al. 2011: 254) - they show how the eye moves through space. Originally they were a concept by D. Noton and L. Stark who referred a scan path to a fixed path, characteristic to a particular participant and viewing pattern (K. Holmqvist et al. 2011, see also A. Duchowski 2007). Scan paths describe a complete saccade-fixate-saccade sequence (Poole, Ball 2006). The length of a scan path is given in pixels and is the sum of the distances between the gazepoint samples (J.H. Goldberg/ X. Kotval 1999). As such a scan path for an individual participant is a graphic representation of all the fixations and saccades on the stimuli, one after another (M. Płużyczka 2015), so it is possible to see what the visual activity of the participant was. However, in case the amount of data visualized is big (for example when the experiment is long or the task is complicated), scan paths become visually cluttered and hard to read. Heat maps are an example of attention maps. They show the distribution of gaze points and fixations. In other words, they visualize eye-tracking data in a quick and very intuitive way - parts of the stimulus with many fixations or data samples are shown with warm colours (red) and those with few or none - with colder colours (blue) (K. Holmqvist et al. 2011). Heat maps 
are very attractive representations but one should be really carefully when drawing conclusions on the basis of them as they only show where the participants look but don't explain why they do it (K. Holmqvist et al. 2011). They also don't give any temporal information about fixations (M. Raschke et al. 2014). AOI sequence chart, though, helps to visualize the sight activity of participants in time - it shows temporal order at which the AOIs were looked at (were hit) by the participant, i.e. it shows the order in which AOIs are fixated. It gives the researcher information about the relative prominence of every AOI within the task (T. Tullis/ B. Albert 2013).

\section{Conclusions}

In $1596 \mathrm{Du}$ Laurens, a French anatomist and medical scientist, said the eyes are windows of the mind (R.P.G. van Gompel et al. 2007). Not so long ago were eye movements associated only with physiology, but nowadays they are believed to be a precise mapping of cognitive processes and external stimuli of visual nature interactions (P. Soluch/ A. Tarnowski 2013) and indicators of some brain processes. Eye movements are the reflection of language processing as well (P. Soluch/ A. Tarnowski 2013). It is a fact that eye movements reveal much information about the way mind and brain work (R.P.G. van Gompel et al. 2007).

Because of the growing awareness of the role of eye movements, eye tracking is getting more and more popular although it is not new. Only lately has it become used in the field of linguistics and translation studies although the history of contemporary eye-tracking research starts in the mid-1970s. As it is based on the eye movements, it helps to verify and complement the previous findings, but it also gives more possibilities of conducting a very useful and interesting experiments in the field of linguistics based on empirical research.

The aim of the article was to give a brief description of the most common, and at the same time the most useful, eye-tracking parameters that can be used in any type of eye-tracking research. The reason to do this was my own research project based on eye-tracking methodology and the wish to make the whole concept of eye-tracking research easier to understand and more popular in a linguistic society.

\section{References}

Andrychowicz-Trojanowska, A. (2015), Uwaga wzrokowa ucznia $w$ pracy $z$ podręcznikiem do nauki języka angielskiego. In: Komunikacja Specjalistyczna 9, 104-124.

Andrychowicz-Trojanowska, A. (2016), Okulografia $w$ glottodydaktyce na przyktadzie badań własnych. In: Komunikacja Specjalistyczna 11, 103-121.

Bonek, A. (2016), Ergonomizacja procesu tlumaczenia pisemnego. Wyniki badania okulograficznego. In: Lingwistyka Stosowana/ Applied Linguistics/ Angewandte Linguistik 20, 19-30.

Chmiel, A./ I. Mazur (2013), Eye Tracking Sight Translation Performed by Trainee Interpreter. In: C. Way/ S. Vandepitte/ R. Meylaerts/ M. Bartłomiejczyk (eds.), 
Tracks and Treks in Translation Studies. Amsterdam/ Philadelphia, 189-205.

Cowen, L./ L.J. Ball/ J. Delin (2002), An eye-movement analysis of web-page usability. In: X. Faulkner/ J. Finlay/ F. Détienne (eds.), People and Computers XVI - Memorable yet Invisible: Proceedings of HCI 2002. London, 317-335.

Duchowski, A. (2007), Eye Tracking Methodology. Theory and Practice. New York.

Duffy, S.A. (1992), Eye movements and complex comprehension processes. In: K. Rayner (ed.) Eye movements and visual cognition: Scene perception and reading. New York, 462-471.

Goldberg, J.H./ X. Kotval (1999), Computer interface evaluation using eye movements: Methods and constructs. In: International Journal of Industrial Ergonomics 24, 631-645.

Gompel van, R.P.G./ M.H. Fischer/ S.M. Wayne/ R.L. Hill (2007), Eye-Movement Research: An Overview of Current and Past Developments. In: R.P.G. van Gompel/ M.H. Fischer/ W.S. Murray/ R.L. Hill (eds.), Eye movements: A window on mind and brain. Elsevier, 1-28.

Grobelny, J./ K. Jach/ M. Kuliński/ R. Michalski (2006), Śledzenie wzroku w badaniach jakości użytkowej oprogramowania. Historia i mierniki. (URL

https://repin.pjwstk.edu.pl/xmlui/bitstream/handle/186319/166/Kansei\%202006_Gr obelny.pdf? sequence=1). [Date of Access: 29.12.2016].

Grucza, S. (2011), Lingwistyka antropocentryczna a badania okulograficzne. In: Lingwistyka Stosowana/ Applied Linguistics/ Angewandte Linguistik 4, 149-162.

Grucza, S. (2013), Heat Maps, Gaze Plots... And What Next? The Access to Translation Competences and Translation Processes. In: S. Grucza/ M. Płużyczka/ J. Zając (eds.), Translation Studies and Eye-Tracking Analysis. Frankfurt/ M., 15-31.

Grucza, S. (2016), W sprawie translatoryki okulograficznej. In: Lingwistyka Stosowana/ Applied Linguistics/ Angewandte Linguistik 20, 51-61.

Grucza, S./ M. Płużyczka/ P. Soluch (2014), Widziane inaczej. Z polskich badań eyetrackingowych. Warszawa.

Grucza, S./ M. Płużyczka/ J. Zając (2013), Eye-Tracking Supported Translation Studies at the University of Warsaw (Instead of Introduction). In: S. Grucza/ M. Płużyczka/ J. Zając (eds.), Translation Studies and Eye-Tracking Analysis. Frankfurt/ M., 7-14.

Holmqvist, K./ M. Nyström/ R. Andersson/ R. Dewhurst/ H. Jarodzka/ J. van de Weijer (2011), Eye tracking. A comprehensive guide to methods and measures. Oxford:.

Jacob, R.J.K./ K.S. Karn (2003), Eye Tracking in Human-Computer Interaction and Usability Research: Ready to Deliver the Promises. In: J. Hyönä/ R. Radach/ H. Deubel (eds.), The Mind's Eye: Cognitive and Applied Aspects of Eye Movement Research. Amsterdam, 573-605.

Just, M.A./ P.A. Carpenter (1976), Eye fixations and cognitive processes. In: Cognitive Psychology 8, 441-480.

Krejtz, I./ A. Szarkowska/ K. Krejtz (2013), The Effects of Shot Changes on Eye Movements in Subtitling. In: Journal of Eye Movement Research 6(5), 1-12.

Kudłaj, A./ J. Nowakowska/ M. Smolak/ M. Zając/ S. Grucza (2014), Architektura bankowych witryn internetowych a percepcja i retencja informacji. In: S. Grucza/ 
M. Płużyczka/ P. Soluch (eds.), Widziane inaczej. Z polskich badań eyetrackingowych, Warszawa, 19-67.

Lorigo, L./ M. Haridasan/ H. Brynjarsdóttir/ L. Xia/ T. Joachims/ G. Gay/ L. Granka/ F. Pellacini/ B. Pan (2008), Eye Tracking and Online Search: Lessons Learned and Challenges Ahead. In: Journal of the American Society for Information Science and Technology 59(7), 1041-1052.

Martinez-Conde, S./ S.L. Macknik/ D.H. Hubel (2004), The role of fixational eye movements in visual perception. In: Nature Reviews Neuroscience 5(3), 229-240.

Płużyczka, M. (2013), Eye-Tracking Supported Research Into Sight Translation. Lapsological Conclusions. In: S. Grucza/ M. Płużyczka/ J. Zając (eds.), Translation Studies and Eye-Tracking Analysis. Frankfurt/ M., 105-138.

Płużyczka, M. (2015), Tłumaczenie a vista. Rozważania teoretyczne $i$ badania eyetrackingowe. Warszawa.

Poole, A./ L.J. Ball (2006), Eye Tracking in HCI and Usability Research. In: C. Ghaoui (ed.) Encyclopedia of Human Computer Interaction. Hershey, 211-219.

Poole, A./ L.J. Ball/ P. Phillips (2004), In search of salience: A response time and eye movement analysis of bookmark recognition. In: S. Fincher/ P. Markopolous/ D. Moore/ R. Ruddle (eds.), People and Computers XVIII-Design for Life: Proceedings of HCI 2004. London, 363-378.

Raschke M./ T. Blascheck/ M. Burch (2014), Visual Analysis of Eye Tracking Data. In: W. Huang (ed.) Handbook of Human Centric Visualization. New York etc. 391-409.

Rayner, K. (1978), Eye Movements in Reading and Information Processing. In: Psychological Bulletin 85, 618-660.

Rayner, K. (1998), Eye Movements in Reading and Information Processing: 20 Year of Research. In: Psychological Bulletin 124(3), 372-422.

Rayner, K./ C.M. Rotello/ A.J. Stewart/ J. Keir/ S.A. Duffy (2001), Integrating Text and Pictorial Information: Eye Movements When Looking at Print Advertisements. In: Journal of Experimental Psychology: Applied 7(3), 219-226.

Renshaw, J.A./ J.E. Finlay/ D. Tyfa/ R.D. Ward (2004), Understanding visual influence in graph design through temporal and spatial eye movement characteristics. In: Interacting with Computers 16, 557-578.

Soluch, P./ A. Tarnowski (2013), Eye-Tracking Methods and Measures. In: S. Grucza/ M. Płużyczka/ J. Zając (eds.), Translation Studies and Eye-Tracking Analysis. Frankfurt/ M., 85-104.

Szarkowska, A./ I. Krejtz/ K. Krejtz/ A. Duchowski (2013), Harnessing the Potential of Eye-Tracking for Media Accessibility. In: S. Grucza/ M. Płużyczka/ J. Zając (eds.), Translation Studies and Eye-Tracking Analysis. Frankfurt/ M., 153-183.

Tullis, T./ B. Albert (2013), Measuring the User Experience. Collecting, Analyzing, and Presenting Usability Metrics. Elsevier.

\section{Internet sources:}

http://www.neurodevice.pl/en/services/eye-tracking [Date of access: 28.12.2016].

lelo.uw.edu.pl [Date of access 24.11.2017]. 